\title{
Metabolismo de plantas de cana-de-açúcar cultivadas in vitro sob diferentes concentrações de nitrogênio(1)
}

\author{
Virgínia Maria Tenorio Sabino Donato ${ }^{(2)}$, Arnóbio Gonçalves de Andrade ${ }^{(3)}$, Eidy Simões de Souza ${ }^{(4)}$ \\ e José Geraldo Eugênio de França(4)
}

\begin{abstract}
Resumo - Variedades de cana-de-açúcar (RB 732577, RB 83102, RB 75126, CB 45-3, Caiana e Co 997) foram cultivadas in vitro em meio nutritivo básico MS com diferentes concentrações de N $(9,83 \mathrm{mM}$, 7,37 mM, 4,92 mM, 2,46 mM, 0,49 mM e 0,0 mM), com o objetivo de avaliar a eficiência no processo de assimilação desse elemento. Após 45 dias de cultivo, foram determinados os ganhos de biomassa e os teores de amônio, aminoácidos e açúcares solúveis. A variedade Co 997 apresentou maior ganho de biomassa e maior quantidade de $\mathrm{N}$ incorporado em aminoácidos livres em relação às demais variedades, sugerindo maior eficiência no processo de assimilação. Os teores mais elevados de amônio foram observados nas variedades RB 83102 e RB 75126, quando cultivadas em meio desprovido de N, mostrandose menos eficientes no processo de assimilação uma vez que apresentaram os menores valores de aminoácidos livres nas mesmas condições de cultivo.
\end{abstract}

Termos para indexação: Saccharum, biomassa, aminoácido, fixação do nitrogênio.

\section{Metabolism of sugar cane plant cultivated in vitro at different nitrogen levels}

\begin{abstract}
Sugar cane varieties (RB 732577, RB 83102, RB 75126, CB 45-3, Caiana and Co 997) were cultivated in vitro at basic MS nutritive media with different $\mathrm{N}$ levels $(9.83 \mathrm{mM}, 7.37 \mathrm{mM}, 4.92 \mathrm{mM}$, $2.46 \mathrm{mM}, 0.49 \mathrm{mM}$ and $0.0 \mathrm{mM}$ ), in order to evaluate the efficiency in the assimilation process of this element. After 45 days of cultivation, the biomass and the ammonium, amino acid and soluble sugars contents were determined. Co 997 variety presented higher biomass gain and higher N quantity incorporated to free amino acid, showing higher efficiency in the assimilation process. Higher proportions of ammoniumwere observed on RB 83102 and RB 75126 varieties when cultivated at media without N, suggesting lower efficiency on the assimilation process due to the presence of lower values of free amino acids.
\end{abstract}

Index terms: Saccharum, biomass, amino acids, nitrogen fixation.

\section{Introdução}

A cana-de-açúcar é uma das principais culturas no panorama agrícola brasileiro, ocupando uma área de mais de 4 milhões de hectares. Em 1998, a produção brasileira correspondeu a $27 \%$ da produção

(1)Aceito para publicação em 14 de agosto de 2003.

${ }^{(2)}$ Rua João Ramos, 285/1801 Graças, CEP 52011-080 Recife, PE. E-mail: vmtsdonato@uol.com.br

${ }^{(3)}$ Universidade Federal Rural de Pernambuco, Dep. de Química Vegetal, Rua D. Manoel de Medeiros, s/n, Dois Irmãos, CEP 52171-900 Recife, PE. E-mail arnobio@truenet.com.br

(4)Empresa Pernambucana de Pesquisa Agropecuária, Av. Gal. SanMartin, 1371, Bongi, CEP 50761-000 Recife, PE. E-mail: eidy@ipa.com.br, geugenio@terra.com.br mundial (FAO, 1998). O Estado de São Paulo é o maior produtor, sendo responsável por cerca de $58 \%$ da produção nacional, enquanto Alagoas e Pernambuco contribuem com 12\% (IBGE, 1999).

O N é um constituinte elementar da nutrição das plantas. Na biosfera encontra-se disponível para as plantas em diferentes formas, incluindo o $\mathrm{N}$ molecular $\left(\mathrm{N}_{2}\right)$, amônia ou óxidos de $\mathrm{N}\left(\mathrm{NH}_{3}, \mathrm{NOx}\right)$, $\mathrm{N}$ mineral $\left(\mathrm{NO}_{3}{ }^{-}\right.$e $\left.\mathrm{NH}_{4}{ }^{+}\right)$e $\mathrm{N}$ orgânico como aminoácidos e peptídeos (Shantharam \& Mattoo, 1997; Wirén et al., 1997). Na agricultura, o N é determinante na produção das culturas, além de ser um dos fertilizantes que mais participam do sistema agrícola (Mae, 1997). Sua assimilação está diretamente relacionada com o metabolismo do $\mathrm{C}$, que fornece energia na forma de esqueletos de $\mathrm{C}$ necessá- 
rios para converter o $\mathrm{N}$ inorgânico em compostos orgânicos (Peuke \& Jeschke, 1993).

A fixação biológica do $\mathrm{N}_{2}(\mathrm{FBN})$ é um processo significativo que, segundo estimativas, fornece entre 139 milhões e 170 milhões de toneladas de $\mathrm{N}$ por ano para a biosfera, valores superiores aos $65 \mathrm{mi}$ lhões aplicados como fertilizantes. Diante do custo atual da energia fóssil e da necessidade de fertilizantes nitrogenados para a produção de alimentos, é grande o interesse pela FBN e o melhoramento da sua eficiência (Pimentel, 1998). De acordo com Bergersen (1980), a FBN pode contribuir com um aumento no conteúdo de $\mathrm{N}$ das plantas hospedeiras, e este aumento pode ser mensurado por meios diretos como a determinação do $\mathrm{N}$ total, proteína, além dos teores de amônio, aminoácidos livres e nitrato.

Entre as não leguminosas, a cana-de-açúcar é uma das culturas que mais se beneficia com o processo da fixação biológica do $\mathrm{N}_{2}$ (Cavalcante \& Döbereiner, 1988).

Acredita-se que a capacidade de fixação biológica do $\mathrm{N}_{2}$, na cana-de-açúcar, esteja relacionada com as características genéticas das cultivares (Urquiaga et al., 1992). No entanto, segundo Boddey \& Döbereiner (1995), poucos trabalhos têm sido publicados com o objetivo de quantificar a contribuição do $\mathrm{N}_{2}$ fixado biologicamente pela cana-de-açúcar. Acredita-se que isto ocorra pela dificuldade de controlar a atmosfera de crescimento das plantas no campo, o que pode tornar a significância agronômica dos resultados pouco confiáveis (Matsui et al., 1981). Utilizando a técnica do cultivo in vitro, é possível manipular as condições de crescimento das plantas, e assim, viabilizar trabalhos com a finalidade de analisar a contribuição do $\mathrm{N}_{2}$ fixado biologicamente.

Este trabalho teve como objetivo estudar o efeito de diferentes concentrações de $\mathrm{N}$ em variedades de cana-de-açúcar, sob condições de cultivo in vitro.

\section{Material e Métodos}

O material vegetal utilizado foi fornecido pela estação experimental de Itapirema do IPA (Empresa Pernambucana de Pesquisa Agropecuária). Foram utilizados rebolos (cana semente) das variedades RB 732577, RB 83102, RB 75126, CB 45-3, Caiana e Co 997.
Inicialmente, as gemas dos rebolos foram individualizadas, sendo parte destinada ao tratamento com Kasugamicina ( $3 \mathrm{~mL} / \mathrm{L}$ ), em que permaneceram submersas por 5 minutos e, em seguida, foram secadas ao ar. A outra parte das gemas foi submetida a um tratamento térmico de $52,5^{\circ} \mathrm{C}$, durante 30 minutos. Subseqüentemente foram plantadas em bandejas contendo substrato estéril (Plantimax), e mantidas em casa de vegetação.

Aos 20 dias após o plantio, as plantas foram pulverizadas com solução de Kasugamicina ( $3 \mathrm{~mL} / \mathrm{L}$ ). Uma semana após a pulverização com Kasugamicina e 21 dias após o tratamento térmico, os brotos foram seccionados e lavados em água corrente. Em seguida foram eliminadas as folhas, ficando apenas uma porção com aproximadamente $2,5 \mathrm{~cm}$ de comprimento (minitoletes), contendo o meristema apical. Posteriormente, os minitoletes passaram por um processo de assepsia que consistiu na imersão em álcool $70 \%$ (v/v) por 1 minuto, seguida de imersão em solução de hipoclorito de sódio $2 \%(\mathrm{~m} / \mathrm{v})$ durante $20 \mathrm{mi}$ nutos e, finalmente, foram lavados três vezes em água destilada esterilizada. Após esse processo, os ápices caulinares foram isolados e cultivados em meio nutritivo, descrito por Liu (1980).

Após 60 dias de cultivo, quando totalmente diferenciada, a planta matriz proveniente do ápice caulinar isolado foi multiplicada sucessivamente a cada 15 dias, por quatro períodos e cultivadas no meio descrito por Liu (1980).

Com a finalidade de verificar a presença das bactérias Acetobacter diazotrophicus e Herbaspirillum spp., a planta matriz foi submetida a um teste de infecção utilizando o método descrito por Döbereiner et al. (1995). O experimento foi constituído de 36 tratamentos, formados por seis variedades de cana-de-açúcar (RB 732577 , RB 83102, RB 75126, CB 45-3, Caiana e Co 997) em combinação fatorial com seis meios nutritivos, que consistiram no meio nutritivo básico descrito por Murashige \& Skoog (1962) (MS) com modificações na concentração original de $\mathrm{N}(9,83 \mathrm{mM}, 7,37 \mathrm{mM}, 4,92 \mathrm{mM}, 2,46 \mathrm{mM}, 0,49 \mathrm{mM}$ e $0,0 \mathrm{mM}$ ).

O experimento, com 10 repetições por tratamento, foi conduzido em sala de crescimento com temperatura de $24 \pm 1^{\circ} \mathrm{C}$, fotoperíodo de 16 horas e intensidade luminosa de $56 \mu \mathrm{mol} / \mathrm{m}^{2} / \mathrm{s}$, onde permaneceram por 45 dias. Foram utilizados como parâmetros de avaliação a massa da matéria seca e os teores de açúcares solúveis, amônio e aminoácidos livres. Os resultados obtidos foram submetidos à análise de variância e as médias dos parâmetros comparadas pelo teste Tukey a 5\% de probabilidade. 
Com o objetivo de determinar a massa da matéria fresca do explante inoculado, cada pote foi submetido a pesagem antes (massa inicial) e depois (massa final) da inoculação das plantas. Depois de inoculadas, sob condições assépticas, em meio de cultura modificado, as plantas foram mantidas em sala de crescimento com temperatura de $24 \pm 1^{\circ} \mathrm{C}$, fotoperíodo de 16 horas e intensidade luminosa de $56 \mu \mathrm{mol} / \mathrm{m}^{2} / \mathrm{s}$, durante 45 dias.

Amostras de três repetições de cada tratamento foram armazenadas em etanol 80\% (v/v) para posterior determinação das porções solúveis. As amostras foram maceradas, filtradas e, em seguida, com adição de clorofórmio, separadas as frações solúveis, a partir das quais foram determinados os teores de açúcares solúveis segundo o método descrito por Yemm \& Willis (1954). A determinação do amônio foi realizada de acordo com o método descrito por Mitchell (1972), e a solução de hipoclorito de sódio foi substituída por dicloroisocianurato de sódio, segundo Felker (1977). Para determinação de aminoácidos livres foi utilizado o método descrito por Yemm \& Cocking (1955).

\section{Resultados e Discussão}

A maioria das variedades não apresentou diferença em ganho de biomassa, quando cultivadas em todas as concentrações de N (Tabela 1), embora tenha sido observada redução no crescimento dos perfilhos em todas as variedades no meio com 2,46 mM. Como o $\mathrm{N}$ está diretamente relacionado com o crescimento das plantas (Lainé et al., 1995), o ganho de biomassa avalia, além da eficiência no processo de assimilação desse elemento, uma possível contribuição da fixação biológica em algumas variedades de cana-deaçúcar.

Entre as variedades avaliadas, a Co 997 destacouse, pois não houve diferença no ganho de biomassa quando cultivada nas diferentes concentrações de nitrogênio. Além disso, essa variedade apresentou aproximadamente $42 \%$ a mais de biomassa em relação à média de todas as variedades cultivadas na ausência de N, o que pode representar maior potencial de fixação de $\mathrm{N}_{2}$ em relação às demais variedades.

$\mathrm{Na}$ análise do teor de carboidratos solúveis, verificou-se que a interação entre meio nutritivo com diferentes concentrações de $\mathrm{N}$ e variedades não foi significativa (Tabela 2). Quando cultivada sem N, a Co 997 apresentou menor teor de carboidratos solúveis em relação às demais variedades. Os carboidratos solúveis devem ter sido consumidos durante o processo de redução do N, pois, nas mesmas condições, observou-se que essa variedade apresentou maior teor de aminoácidos livres (Tabela 3). O teor de carboidratos nas variedades mostrou redução de acordo com o

Tabela 1. Massa ( $\mathrm{g}$ ) da matéria seca acumulada em plantas de cana-de-açúcar, após 45 dias de cultivo in vitro, em meio de cultivo com diferentes níveis de nitrogênio ${ }^{(1)}$.

\begin{tabular}{cllllll}
\hline Níveis de $\mathrm{N}^{(2)}(\mathrm{mM})$ & RB 83102 & Caiana & RB 75126 & RB 732577 & Co 997 & CB 45-3 \\
\hline 9,83 & $0,41 \mathrm{abA}$ & $0,37 \mathrm{abA}$ & $0,37 \mathrm{abA}$ & $0,27 \mathrm{bAB}$ & $0,43 \mathrm{aA}$ & $0,33 \mathrm{abA}$ \\
7,37 & $0,47 \mathrm{aA}$ & $0,37 \mathrm{abA}$ & $0,37 \mathrm{abA}$ & $0,40 \mathrm{abAB}$ & $0,40 \mathrm{abA}$ & $0,30 \mathrm{bA}$ \\
4,92 & $0,40 \mathrm{aA}$ & $0,37 \mathrm{aA}$ & $0,33 \mathrm{aA}$ & $0,40 \mathrm{aA}$ & $0,30 \mathrm{aA}$ & $0,33 \mathrm{aA}$ \\
2,46 & $0,33 \mathrm{aAB}$ & $0,33 \mathrm{aA}$ & $0,30 \mathrm{aAB}$ & $0,30 \mathrm{aAB}$ & $0,30 \mathrm{aA}$ & $0,30 \mathrm{aA}$ \\
0,49 & $0,20 \mathrm{abB}$ & $0,23 \mathrm{abAB}$ & $0,17 \mathrm{bBC}$ & $0,27 \mathrm{abAB}$ & $0,33 \mathrm{aA}$ & $0,23 \mathrm{abAB}$ \\
0,00 & $0,20 \mathrm{aB}$ & $0,17 \mathrm{aB}$ & $0,10 \mathrm{aC}$ & $0,17 \mathrm{aB}$ & $0,23 \mathrm{aA}$ & $0,10 \mathrm{aB}$ \\
\hline
\end{tabular}

${ }^{(1)}$ Médias seguidas pela mesma letra, minúscula para variedades e maiúscula para níveis de N, não diferem entre si a 5\% de probabilidade, pelo teste de Tukey. ${ }^{(2)}$ Meio nutritivo com sais do MS, acrescido de sacarose e diferentes concentrações de nitrogênio.

Tabela 2. Teor de açúcares solúveis (mg/g de matéria fresca) em plantas de cana-de-açúcar cultivadas in vitro por 45 dias, em meio de cultivo com diferentes concentrações de nitrogênio ${ }^{(1)}$.

\begin{tabular}{cllllll}
\hline Níveis de ${ }^{(2}(\mathrm{mM})$ & RB 83102 & Caiana & RB 75126 & RB 732577 & Co 997 & CB 45-3 \\
\hline 9,83 & $0,1879 \mathrm{aB}$ & $0,1773 \mathrm{aB}$ & $0,1468 \mathrm{aC}$ & $0,4316 \mathrm{aB}$ & $0,1323 \mathrm{aAB}$ & $0,1265 \mathrm{aB}$ \\
7,37 & $0,1854 \mathrm{aB}$ & $0,1870 \mathrm{aB}$ & $0,1672 \mathrm{aC}$ & $0,3507 \mathrm{aB}$ & $0,0880 \mathrm{aB}$ & $0,2436 \mathrm{aB}$ \\
4,92 & $0,1929 \mathrm{aB}$ & $0,2137 \mathrm{aB}$ & $0,2102 \mathrm{aC}$ & $0,2749 \mathrm{aB}$ & $0,1738 \mathrm{aAB}$ & $0,1691 \mathrm{aB}$ \\
2,46 & $0,2052 \mathrm{aB}$ & $0,3975 \mathrm{aB}$ & $0,2864 \mathrm{aBC}$ & $0,4920 \mathrm{aB}$ & $0,2362 \mathrm{aAB}$ & $0,2956 \mathrm{aB}$ \\
0,49 & $0,6316 \mathrm{aA}$ & $0,4110 \mathrm{abB}$ & $0,6099 \mathrm{aAB}$ & $0,4435 \mathrm{abB}$ & $0,2226 \mathrm{bAB}$ & $0,3930 \mathrm{abAB}$ \\
0,00 & $0,7187 \mathrm{abA}$ & $0,8691 \mathrm{aA}$ & $0,7954 \mathrm{abA}$ & $0,9282 \mathrm{aA}$ & $0,4652 \mathrm{bA}$ & $0,6322 \mathrm{abA}$ \\
\hline
\end{tabular}

${ }^{(1)}$ Médias seguidas pela mesma letra, minúscula para variedades e maiúscula para níveis de $\mathrm{N}$, não diferem entre si a $5 \%$ de probabilidade, pelo teste de Tukey. ${ }^{(2)}$ Meio nutritivo com sais do MS, acrescido de sacarose e diferentes concentrações de nitrogênio. 
aumento nos níveis de N (Tabela 2). Resultados similares foram observados por Veith \& Komor (1993), quando cultivaram células de cana-de-açúcar em meios de cultura com baixa concentração de $\mathrm{N}$ e obtiveram altos teores de sacarose e baixo teor de aminoácidos.

O teor de carboidratos solúveis não variou nos meios de cultura com 9,83, 7,37, 4,92 e 2,46 mM de $\mathrm{N}$, enquanto nos meios com 0,49 e 0,0 mM apresentou diferença entre as variedades RB 732577 e Caiana (Tabela 2). Após 30 dias de cultivo, verificou-se que quanto maior o nível de $\mathrm{N}$ no meio, menor foi o teor de açúcar acumulado em todas as variedades, exceto na RB 732577. O maior teor de açúcar acumulado pela variedade RB 732577, na maioria dos tratamentos, pode indicar uma deficiência na assimilação do $\mathrm{N}$ disponível ou que esta variedade, possivelmente, seja mais rica em açúcar. A variedade Co 997 nas mesmas condições de cultivo apresentou os menores teores de carboidratos solúveis, em relação às demais variedades (Tabela 2).

A absorção de $\mathrm{N}$ é dependente da disponibilidade de energia (Crawford, 1995). Os carboidratos solúveis são fonte de energia para a assimilação do $\mathrm{N}$ reduzido (Souza, 1995). Em plantas de trigo, a capacidade das raízes em absorver $\mathrm{N}$ foi diretamente correlacionada com o suprimento de carboidratos (Huppe \& Turpin, 1994). Isso explica, em parte, a variação diária na taxa de absorção de $\mathrm{N}$ nas plantas em razão da maior disponibilidade de carboidratos (Rufty et al., 1989).

As plantas cultivadas in vitro não dispõem de condições adequadas de iluminação para a realização da fotossíntese que sustente o crescimento, sendo necessário adicionar ao meio nutritivo uma fonte de carbono. A sacarose $(3 \% \mathrm{~m} / \mathrm{v})$ é o carboidrato mais utilizado nos meios de cultura (Caldas et al., 1998). No entanto, na cana-de-açúcar, foram utilizados $2 \%$ de sacarose para reduzir o seu metabolismo e aumentar o período de subcultivo, o que pode ter limitado o processo de assimilação de $\mathrm{N}$ pelas variedades.

De acordo com Bergersen (1980), a FBN pode contribuir com um aumento no conteúdo de $\mathrm{N}$ das plantas hospedeiras, sendo que esse aumento pode ser mensurado por meios diretos como a determinação do $\mathrm{N}$ total e proteína, além dos teores de amônio, aminoácidos livres e nitrato. $\mathrm{O}$ teor de $\mathrm{N}$ amoniacal nas plantas de cana-de-açúcar diferiu entre as variedades (Tabela 3). No entanto, foi possível observar que o conteúdo de amônio foi bastante uniforme entre as variedades RB 75126, RB 732577, Co 997, CB 45-3 e Caiana, independentemente da concentração de $\mathrm{N}$ contida nos meios de cultura.

Os resultados observados nas variedades cultivadas em meio de cultura desprovido de $\mathrm{N}$ demonstraram que as variedades RB 83102 e RB 75126 não apresentaram diferenças em relação à concentração de amônio e foram responsáveis pelas maiores con-

Tabela 3. Teor de amônio e de aminoácidos livres na matéria fresca de plantas de cana-de-açúcar cultivadas in vitro por 45 dias, em meio de cultivo com diferentes concentrações de nitrogênio ${ }^{(1)}$.

\begin{tabular}{ccccccc}
\hline Níveis de $\mathrm{N}^{(2)} \mathrm{mM}$ & $\mathrm{RB} 83102$ & Caiana & RB 75126 & RB 732577 & Co 997 & CB 45-3 \\
\hline & & \multicolumn{5}{c}{ Teor de amônio $(\mu$ moles/g de massa fresca) } \\
9,83 & $0,156 \mathrm{aA}$ & $0,076 \mathrm{cAB}$ & $0,097 \mathrm{bA}$ & $0,086 \mathrm{cbA}$ & $0,070 \mathrm{cA}$ & $0,00 \mathrm{dA}$ \\
7,37 & $0,118 \mathrm{aAB}$ & $0,098 \mathrm{bA}$ & $0,102 \mathrm{abA}$ & $0,056 \mathrm{cAB}$ & $0,073 \mathrm{cA}$ & $0,00 \mathrm{dA}$ \\
4,92 & $0,077 \mathrm{abC}$ & $0,071 \mathrm{abAB}$ & $0,086 \mathrm{aAB}$ & $0,064 \mathrm{bAB}$ & $0,063 \mathrm{bA}$ & $0,00 \mathrm{cA}$ \\
2,46 & $0,027 \mathrm{dC}$ & $0,095 \mathrm{abA}$ & $0,096 \mathrm{aA}$ & $0,078 \mathrm{bcA}$ & $0,066 \mathrm{cA}$ & $0,028 \mathrm{dA}$ \\
0,49 & $0,052 \mathrm{cdC}$ & $0,092 \mathrm{aA}$ & $0,031 \mathrm{~dB}$ & $0,058 \mathrm{bAB}$ & $0,055 \mathrm{cbA}$ & $0,037 \mathrm{dA}$ \\
0,00 & $0,063 \mathrm{aBC}$ & $0,036 \mathrm{bcB}$ & $0,050 \mathrm{abAB}$ & $0,014 \mathrm{~dB}$ & $0,036 \mathrm{bcA}$ & $0,023 \mathrm{cdA}$ \\
\hline \multicolumn{7}{c}{ Teor de aminoácidos livres $(\mu$ moles/g de massa fresca) } \\
9,83 & $27,16 \mathrm{bA}$ & $37,31 \mathrm{aA}$ & $29,81 \mathrm{abA}$ & $25,06 \mathrm{bA}$ & $30,03 \mathrm{abA}$ & $29,59 \mathrm{abA}$ \\
7,37 & $19,56 \mathrm{aA}$ & $23,47 \mathrm{aB}$ & $16,87 \mathrm{aB}$ & $15,71 \mathrm{aB}$ & $23,22 \mathrm{aAB}$ & $22,86 \mathrm{aA}$ \\
4,92 & $11,61 \mathrm{aB}$ & $16,17 \mathrm{aB}$ & $16,03 \mathrm{aB}$ & $10,51 \mathrm{aCB}$ & $16,92 \mathrm{aBC}$ & $12,44 \mathrm{aB}$ \\
2,46 & $2,77 \mathrm{aC}$ & $7,05 \mathrm{aC}$ & $6,24 \mathrm{aC}$ & $4,70 \mathrm{aCD}$ & $9,73 \mathrm{aDC}$ & $8,38 \mathrm{aCB}$ \\
0,49 & $0,54 \mathrm{aC}$ & $1,79 \mathrm{aC}$ & $0,48 \mathrm{aC}$ & $1,92 \mathrm{aD}$ & $7,35 \mathrm{aD}$ & $2,10 \mathrm{aC}$ \\
0,00 & $0,68 \mathrm{aC}$ & $1,75 \mathrm{aC}$ & $0,74 \mathrm{aC}$ & $1,30 \mathrm{aD}$ & $5,28 \mathrm{aD}$ & $1,24 \mathrm{aC}$ \\
\hline
\end{tabular}

${ }^{(1)}$ Médias seguidas pela mesma letra, minúscula para variedades e maiúscula para níveis de N, não diferem entre si a $5 \%$ de probabilidade, pelo teste de Tukey. ${ }^{(2)}$ Meio nutritivo com sais do MS, acrescido de sacarose e diferentes concentrações de nitrogênio. 
centrações, seguidas pelas variedades Co 997, Caiana e CB 45-3 que também não diferiram entre si.

$\mathrm{Na}$ análise da concentração de amônio das variedades cultivadas na ausência de $\mathrm{N}$, verificou-se que a variedade RB 732577 apresentou a menor concentração de amônio. No entanto, a concentração de carboidratos solúveis, analisada nas mesmas condições de cultivo, foi a mais elevada em relação às demais variedades. Nas variedades RB 83102 e RB 75126 observou-se que, apesar de apresentarem as maiores concentrações de amônio, as concentrações de aminoácidos livres foram as menores em relação às demais variedades, o que pode indicar menor eficiência no processo de assimilação do N (Tabela 3 ).

Por outro lado, nas variedades Co 997 e Caiana, que apresentaram a terceira menor concentração de amônio em relação às demais variedades, observouse as duas maiores concentrações de aminoácidos livres, nas mesmas condições de cultivo. Isso pode indicar maior eficiência no processo de assimilação do $\mathrm{N}$, pois, quando avaliada a concentração de carboidratos solúveis, estas variedades apresentaram as menores concentrações, com destaque para a Co 997 (Tabela 2). Considerando que o $\mathrm{N}$ na forma reduzida é incorporado em esqueletos de carbono para, subseqüentemente, gerar os aminoácidos (Majerowicz, 1997), acredita-se que a variedade Co 997 apresenta maior eficiência no processo de assimilação do $\mathrm{N}$, em relação às demais variedades estudadas.

Como as variedades avaliadas estavam infectadas com as bactérias endofíticas A. diazotrophicus e Herbaspirillum spp., fato constatado por meio de testes de infecção realizados de acordo com Döbereiner et al. (1995), poder-se-ia admitir que o conteúdo de amônio encontrado nas variedades, quando cultivadas sem $\mathrm{N}$, seria proveniente do processo de fixação biológica, pois uma característica única dessas bactérias, mais especificamente de A. diazotrophicus, é a capacidade de excretar parte do $\mathrm{N}_{2}$ fixado no meio (Cojho et al., 1993). Segundo Cruz et al. (1995), citado por Baldani et al. (1996), trata-se de amônio, o que também foi constatado em milho quando associado a Azospirillum sp. (Christiansen-Weniger \& Vanderleyden, 1994).

Em média, as plantas cultivadas na maior concentração de $\mathrm{N}(9,83 \mathrm{mM})$, apresentaram maior acúmulo de N de aminoácidos, verificando-se diferença significativa, entre as variedades RB 83102, RB 732577 e Caiana (Tabela 3). Os teores de $\mathrm{N}$ de aminoácidos foram diretamente proporcionais aos níveis de $\mathrm{N}$ contido no meio de cultura. Esses resultados concordam com as observações de Fernandes (1991) e Souza (1995), de que ocorre acúmulo de $\mathrm{N}$ de aminoácidos livres em condições de excesso de nitrogênio.

No meio de cultura desprovido de N, observouse que as variedades apresentaram resultados bem uniformes, destacando-se a variedade Co 997 com aproximadamente 5 umoles de $\mathrm{N}$ de aminoácidos/g de matéria fresca, o que representa um acúmulo de no mínimo $126 \%$ a mais que as outras variedades. Isso pode significar que esta variedade possui maior potencial de fixação do $\mathrm{N}_{2}$ ou maior capacidade de assimilação do $\mathrm{N}$, pois embora tenha apresentado menor teor de amônio (Tabela 3 ) que as variedades RB 83102 e RB 732577, apresentou maior teor de aminoácidos livres que as demais variedades estudadas e ainda apresentou o menor teor de açúcares solúveis, comprovando que mais $\mathrm{C}$ foi consumido para metabolizar o $\mathrm{N}$, provavelmente, fornecido pelas bactérias fixadoras, já que seu conteúdo de aminoácidos foi superior.

\section{Conclusões}

1. A redução dos níveis de nitrogênio não afeta o ganho de biomassa na variedade Co 997.

2. As variedades RB 83102 e RB 75126 são menos eficientes no processo de assimilação do nitrogênio, enquanto a Co 997 é mais eficiente.

\section{Referências}

BALDANI, J. I.; POT, B.; KIRCHHOF, G.; FALSEN, E.; BALDANI, V. L. D.; OLIVARES, F. L.; HOSTE, B.; KERSTERS, K.; HARTMANN, A.; GILLIS, M.; DÖBEREINER, J. Emended description of Herbaspirillum: inclusion of (Pseudomonas) rubrisubalbicans, a mild plant pathogen, as Herbaspirillum rubrissubalbicans comb.nov.; and classification of a group of clinical isolates (EF group 1) as Herbaspirillum species 3. International Journal of Systematic Bacteriology, Reading, v. 14, p. 263-279, 1996. 
BERGERSEN, F. J. Measurement of nitrogen fixation by direct means. In: BERGERSEN, F. J. (Ed.). Methods for evaluating biological nitrogen fixation. New York: A. Wiley-Interscience, 1980. p. 65-110.

BODDEY, R. M.; DÖBEREINER, J. Nitrogen fixation associated with grasses and cereals: recent progress and perspectives for the future. Fertilizer Research, v. 4 p. 1-10, 1995.

CALDAS, L. S.; HARIDASAN, P.; FERREIRA, M. E. Meios nutritivos. In: TORRES, A. C.; CALDAS, L. S.; BUSO, A. J. (Ed.). Cultura de tecidos e transformação de plantas. Brasília: Embrapa-SPI/Embrapa-CNPH, 1998. v. 1, p. $87-132$.

CAVALCANTE, V. A.; DÖBEREINER, J. A new acidtolerant nitrogen-fixing bacterium associated with sugarcane. Plant and Soil, The Hague, v. 108, p. 23-31, 1988.

CHRISTIANSEN-WENIGER, C.; VANDERLEYDEN, J. Ammonium-excreting Azospirillum sp. become intracellulary establised in maize (Zea mays L.) to nodules. Biology and Fertility of Soils, Berlin, v. 17,p. 1-8, 1994.

COJHO, E. H.; REIS, V.M.; SCHENBREG, A. C. G.; DÖBEREINER, J. Interations of Acetobacter diazotrophius with an amylolytic yeast in nitrogen-free batch culture. FEMS Microbiology Letters, v. 106, p. 341-346, 1993.

CRAWFORD, N. M. Nitrate: nutrient and signal for plant growth. Plant Cell, Rockville, v. 7, p. 859-868, 1995.

DÖBEREINER, J.; BALDANI, V. L. D.; BALDANI, J. I. Como isolar e identificar bactérias diazotróficas de plantas não-leguminosas. Brasília: Embrapa-SPI; Itaguaí: Embrapa-CNPAB, 1995. 60 p.

FAO (Roma, Itália). Yearbook Production. Rome: 1998. 142 p. (FAO Statistics Series, v. 51, n. 148).

FELKER, P. Microdetermination of nitrogen in seed protein extratcs. Analytical Chemistry, Wasshington, v. 49, 1080 p. 1977.

FERNANDES, M. S. Effects of environmental stress on the relationship of free amino-N to fresh weight of rice plants. Journal of Plant Nutrition, New York, v. 14, n. 1, p. 1155-1164, 1991.

HUPPE, H. C.; TURPIN, D. H. Integration of cardon metabolism and nitrogen metabolism in plant and alga cells. Annual Review Plant Physiology and Plant Molecular Biology, Palo Alto, v. 45, p. 577-607, 1994.
IBGE (Rio de Janeiro). Levantamento sistemático da produção agrícola: pesquisa mensal de previsão e acompanhamento das safras agrícolas no ano civil. Disponível em: <http://www.ibge.gov.br/>.Acesso em: dez. 1999.

LAINÉ, P.; OURRY,A.; BOUCAUD, J. Shoot control of nitrate uptake rates by roots of Brassica napus L.: Effects of localized nitrate supply. Planta, Berlin, v. 196, p. 7783, 1995

LIU, M. C. In vitro methods applied to sugarcane improvement. In: THORPE, T. A. (Ed.). Plant tissue culture. New York: Academic, 1980. p. 99-323.

MAE, T. Physiological nitrogen efficiency in rice: nitrogen utilization, photosynthesis and yield potential. Plant and Soil, The Hague, v. 196, p. 201-210, 1997.

MAJEROWICZ, N. Crescimento, assimilação e teores de compostos nitrogenados em plantas de Catasetum fibriatum (Morren) Lindl. (Orchidaceae) cultivadas in vitro com diferentes fontes de nitrogênio. 1997. 133 f. Tese (Doutorado em Botânica) - Universidade de São Paulo, São Paulo, 1997.

MATSUI, E.; VOSE, P. B.; RODRIGUES, N. S. R.; RUSCHEL, A. P. Use of ${ }^{15} \mathrm{~N}$ enriched gas to determine $\mathrm{N}_{2}$-fixation by undisturbed sugar cane plant in the field. In: VOSE, P. B.; RUSCHEL, A. P. (Ed.). Associative $\mathbf{N}_{2}$ fixation. Boca Raton: CRC Press, 1981. v. 2, p. 153-161.

MITCHELL, H. T. Microdetermination of nitrogen in plant tissue. Journal of Association Official Agriculture, Gaithersburg, v. 55, p. 1-3, 1972.

MURASHIGE, T.; SKOOG, F. A. Revised medium for rapid growth and bioassays with tobacco tissue cultures. Physiologia Plantarum, Copenhagen, v. 15, p. 473-497, 1962.

PEUKE, A. D.; JESCHKE, W. D. The uptake and flow of $\mathrm{C}, \mathrm{N}$ and ions between roots and shoots in Racinus comunis L. - I: growth with ammonium and nitrate as nitrogen source. Journal of Experimental Botany, London, v. 44, p. 1167-1176, 1993.

PIMENTEL, C. Metabolismo de carbono na agricultura tropical. Seropédica: Edur, 1998. 159 p.

RUFTY, T. W.; MACKOWN, C. T.; VOLK, R. J. Effects of altered carbohydrate availability on whole-plant assimilation of ${ }^{15} \mathrm{NO}_{3}$.Plant Physiology, Bethesda, v. 89, p. $457-463,1989$. 
SHANTHARAM, S.; MATTOO, A. K. Enhancing biological nitrogen fixation: an appraisal of current and alternative technologies for $\mathrm{N}$ input into plants. Plant and Soil, The Hague, v. 194, p. 205-216, 1997.

SOUZA, S. R. Efeitos da aplicação foliar de nitrogênio pós-antese sobre as enzimas de assimilação de $\mathbf{N}$ e acúmulo de proteínas em grãos de arroz. 1995. 152 f. Tese (Doutorado em Ciência do Solo) - Universidade Federal Rural do Rio de Janeiro. Seropérdica, 1995.

URQUIAGA, S.; CRUZ, K. H. S.; BODDEY, R. M. Contribution of nitrogen fixation to sugarcane: nitrogen15 and nitrogen-balance estimates. Soil Science Society of America Journal, Madison, v. 56, p. 105-114, 1992.
VEITH, R.; KOMOR, E. Regulation of growth, sucrose storage and ion content in sugarcane cells, measured with suspension cells in continuous culture grown under nitrogen, phosphorus or carbon limitation. Journal of Plant Physiology, Stuttgart, v. 142, p. 414-424, 1993.

WIRÉN, N. V.; GAZZARRINI, S.; FROMMER, W. B. Regulation of mineral nitrogen uptake in plants. Plant and Soil, The Hague, v. 196, p. 191-199, 1997.

YEMM, E. W.; COCKING, E. C. The determination of aminoacid with ninhydrin. Analyst, London, v. 80, p. 209213, 1955.

YEMM, E. W.; WILLIS, A. I. The estimation of carbohydrates in plant extracts by anthrone. Biochemical Journal, London, v. 57, p. 508-514, 1954. 